\title{
Verificação da influência da temperatura e da concentração de cloreto férrico na usinagem fotoquímica do aço inoxidável 304
}

\section{Checking the influence of temperature and ferric chloride concentration in photochemical machining of stainless steel 304}

\author{
1 Adair Gomes de Souza adairgomes@yahoo.com.br \\ ' Carlos Alberto Martins Ferreira
}

\section{Resumo}

Os aços inoxidáveis, por apresentarem alta resistência à corrosão em meios oxidantes, são de grande uso na indústria e como meio de decoração devido a sua aparência e acabamento superficial. Outra utilização dos aços inoxidáveis tem sido na indústria de confecção de produtos decorativos, de placas de identificação, placas comemorativas, de homenagens, joias, etiquetas metálicas e de peças para micro engenharia pelo processo de usinagem fotoquímica, no qual o metal é preparado e atacado com solução de cloreto férrico, gerando altas taxas de corrosão no metal em áreas defınidas, dando forma às peças. 0 presente trabalho tem como objetivo estudar o aço 304 como material usado na usinagem fotoquímica, atacado com solução de cloreto férrico em diferentes concentrações e temperaturas. Para este trabalho, foram realizadas curvas de polarização anódica para se conhecer o potencial de pite do aço 304 em solução de cloreto férrico, nas concentrações 13\%, $20 \%, 30 \%$ e $40 \%$ e temperaturas de $25^{\circ} \mathrm{C}, 35^{\circ} \mathrm{C}$ e $50^{\circ} \mathrm{C}$. Foram analisadas as imagens das amostras após o ataque com solução de cloreto férrico. Observou-se que quanto maior a concentração da solução corrosiva e a temperatura, maior a densidade e o tamanho dos pites formados nas amostras. Os ensaios realizados mostraram que, quanto maior a concentração da solução corrosiva e a temperatura, mais eficiente é o processo de usinagem fotoquímica do aço 304.

Palavras-chave: Corrosão. Camada passive. Pites. Polarização anódica.

\begin{abstract}
The Stainless Steel, due to high corrosion resistance in oxidizing agents, are of great use in industry and for decoration because of their appearance and surface finish. Another use of stainless steels has been in the production of decorative products industry, plaques, commemorative and honors plaques, jewelry, metallic tags and parts for micro engineering from photochemical machining process, where the metal is prepared and attacked with ferric chloride solution generating high corrosion rate of the metal in defined areas, forming parts. The purpose of this research is to study the stainless steel 304, as material used in the photochemical machining, attacked with ferric chloride solution at different concentrations and temperatures. For this research, anodic polarization curves were realized to know the pitting potential of the stainless steel 304 in ferric chloride solution at concentrations of $13 \%, 20 \%, 30 \%$ and $40 \%$ and temperatures of $25^{\circ} \mathrm{C}, 35^{\circ} \mathrm{C}$ and $50^{\circ} \mathrm{C}$. The images of the samples after attack with ferric chloride solution were analyzed. It was observed that the higher the concentration of the corrosive solution, and the temperature, the higher the density and size of pits formed in the samples. The tests performed show that the higher the concentration of the corrosive solution and the temperature, the more efficient the photochemical machining process of stainless steel AISI 304
\end{abstract}

Keywords: Corrosion. Passive layer. Pitting. Anodic polarization.

\section{Como você deve citar?}

SOUZA, Adair Gomes de; FERREIRA, Carlos Alberto Martins. Verificação da influência da temperatura e da concentração de cloreto férrico na usinagem fotoquímica do aço inoxidável 304. Cadernos UniFOA, Volta Redonda, n. 41, p. 47-59, dezembro 2019. 


\section{INTRODUÇÃO}

A usinagem fotoquímica ( $P C M$, do inglês Photochemical Machining) é um dos processos de usinagem não convencional (WEl et al, 2008; EL-HOFY, 2005; ABATE, 1997). O processo emprega o ataque químico com o uso de uma solução corrosiva sobre áreas selecionadas (PATIL; THORAT; KHAKE, 2018; DAVIS; OVERTURF, 1986). A técnica, como usada atualmente, é relativamente moderna e foi estabelecida como um processo industrial há, aproximadamente, cinquenta anos. 0 método de remoção de material na PCM é baseado numa reação de oxirredução, efetuando-se a oxidação do metal e a dissolução do metal com a formação de subprodutos solúveis (ALLEN, 2005; WANGIKAR; PATOWARI; MISRA, 2017).

Os aços inoxidáveis são utilizados atualmente na indústria para a fabricação de peças, tubulações e na fabricação de produtos de uso doméstico, tais como geladeira, fogão, etc. (CARBÓ, 2008). Outra possibilidade está na indústria de confecção de produtos em chapas com alteração na superfície pelo processo de usinagem fotoquímica, o que consiste no ataque químico às chapas de aços inoxidáveis com cloreto férrico em equipamentos específicos (ALLEN; ALMOND, 2004). Na seleção de materiais para o uso na usinagem fotoquímica, é fundamental que seja levado em conta o custo dos aços e a facilidade de serem corroídos pelo processo de ataque químico. 0 uso dos aços inoxidáveis, principalmente os aços austeníticos, tem sido bastante difundido, quando se trata do seu uso no processo de usinagem fotoquímica (TEHRANI; IMANIAN, 2004; AL-ETHARI; ALSULTANI; DAKHIL, 2013; KARJALAINEN; HERTZMAN, 2008).

O presente trabalho tem como objetivo verificar a influência da temperatura e da concentração de cloreto férrico no aço inoxidável 304 como material usado no processo de usinagem fotoquímica (KIM et al, 2017; ZHANG; MENG, 2012). Para este trabalho, foram realizadas curvas de polarização anódica (GENTIL, 2011; GEMELLI, 2001) com a finalidade de se verificar a resistência à corrosão do aço inoxidável 304, quando submetido à variação de temperatura de 25 a $50^{\circ} \mathrm{C}$ e à variação de 13 a $40 \%$ da concentração da solução de cloreto férrico como produto corrosivo usado no processo de usinagem fotoquímica.

O aço inoxidável do tipo AISI 304 é um dos materiais usados para a confecção de placas de identificação, homenagens e ou decorativas, etiquetas metálicas e peças para micro engenharia, conforme ilustra a Figura 1.

Figura 1 - Peças produzidas pelo processo de usinagem fotoquímica.

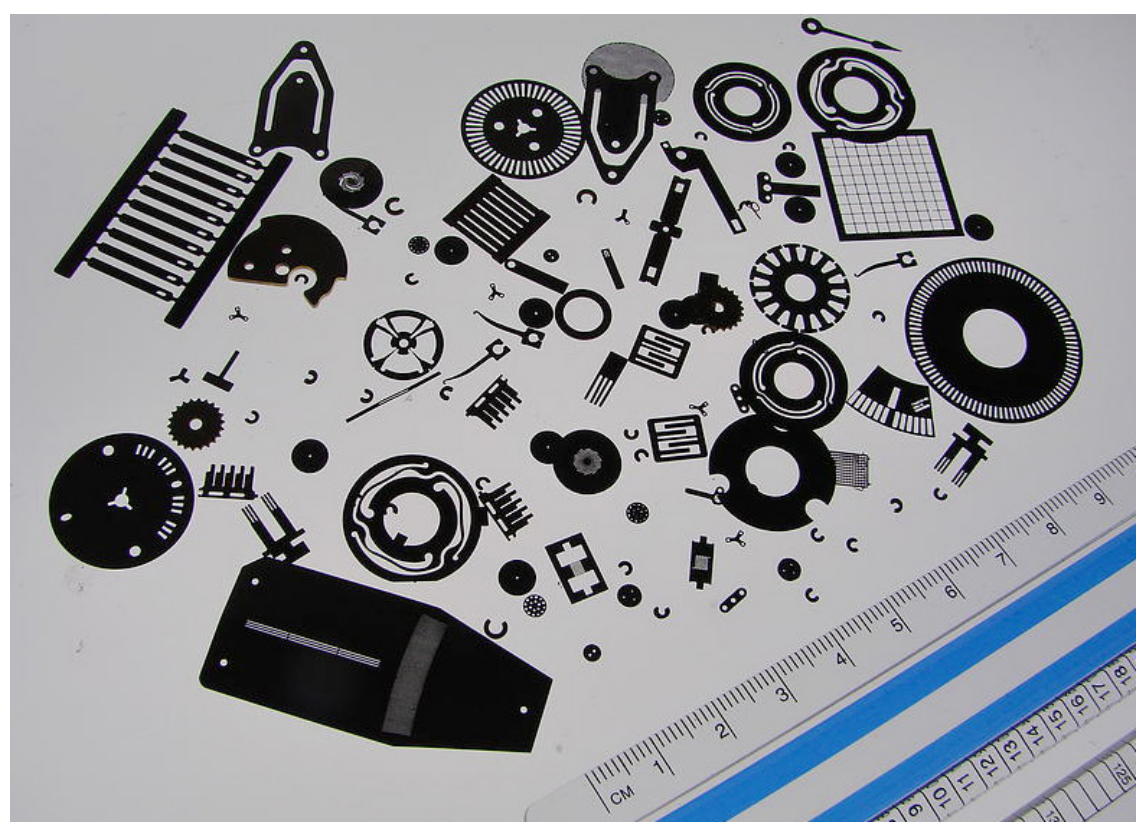

Fonte: http://www.shimifrez.com/ - Acesso em: 26 nov. 2018. 


\section{MATERIAIS E MÉTODOS}

Amostras de aço inoxidável austenítico 304 comercial na forma de barras diâmetro $10 \mathrm{~mm}$, área superficial $0,785 \mathrm{~cm} 2$ foram usadas no presente estudo. A composição química da amostra está apresentada na Tabela 1.

Tabela 1 - Composição química do aço inoxidável 304. (porcentagem em massa)

\begin{tabular}{ccccccccccccc}
\hline Aço & $\mathrm{C}$ & $\mathrm{Mn}$ & $\mathrm{Si}$ & $\mathrm{P}$ & $\mathrm{S}$ & $\mathrm{Cr}$ & $\mathrm{Ni}$ & $\mathrm{Mo}$ & $\mathrm{Nb}$ & $\mathrm{Ti}$ & $\mathrm{N}_{2}$ & $(\mathrm{C}+\mathrm{N})$ \\
\hline 304 & 0,08 & 2 & 1 & 0,045 & 0,03 & $18 / 20$ & $8 / 10,5$ & 0 & 0 & 0 & 0 & 0 \\
\hline \multicolumn{1}{c}{ Fonte: Dos autores, 2018.}
\end{tabular}

Fonte: Dos autores, 2018

\section{PREPARAÇÃO METALOGRÁFICA DAS AMOSTRAS}

Ambas as amostras tiveram um fio de cobre de $2,5 \mathrm{~mm}$ fixado em uma das suas faces e foram embutidas em resina de embutimento de uso metalográfica. A Figura 2 apresenta a resina e as amostras sendo embutidas com a resina após o preparo.

Figura 2 - (a) Resina de embutimento e (b) amostras sendo embutidas com a resina.
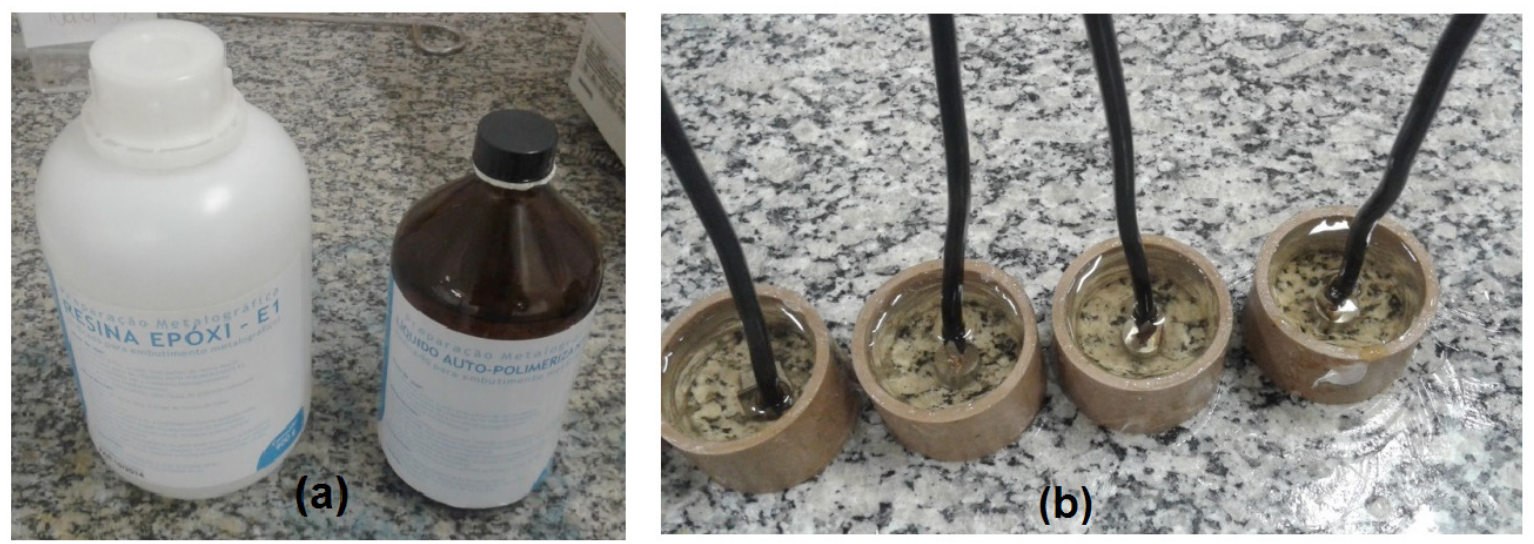

Fonte: Dos autores, 2018.

Após a secagem da resina de embutimento, as amostras embutidas foram lavadas com detergente e água. Foram enxaguadas abundantemente com água destilada e secas com ar quente. As superfícies das amostras foram lixadas com lixa d'água de granulação de 320 mesh, utilizando-se lixadeira metalográfica. A figura 3 apresenta a amostra do aço 304 embutido e a lixadeira metalográfica usada para o lixamento das amostras, preparando a superfície das amostras para o ensaio eletroquímico. 
Figura 3 - Amostra do aço embutida para os ensaios. (a) aço 304, dimensão: diâmetro $10 \mathrm{~mm}$ e área $0,785 \mathrm{~cm}^{2}$ e (b) Lixadeira metalográfica usada para o lixamento das amostras.
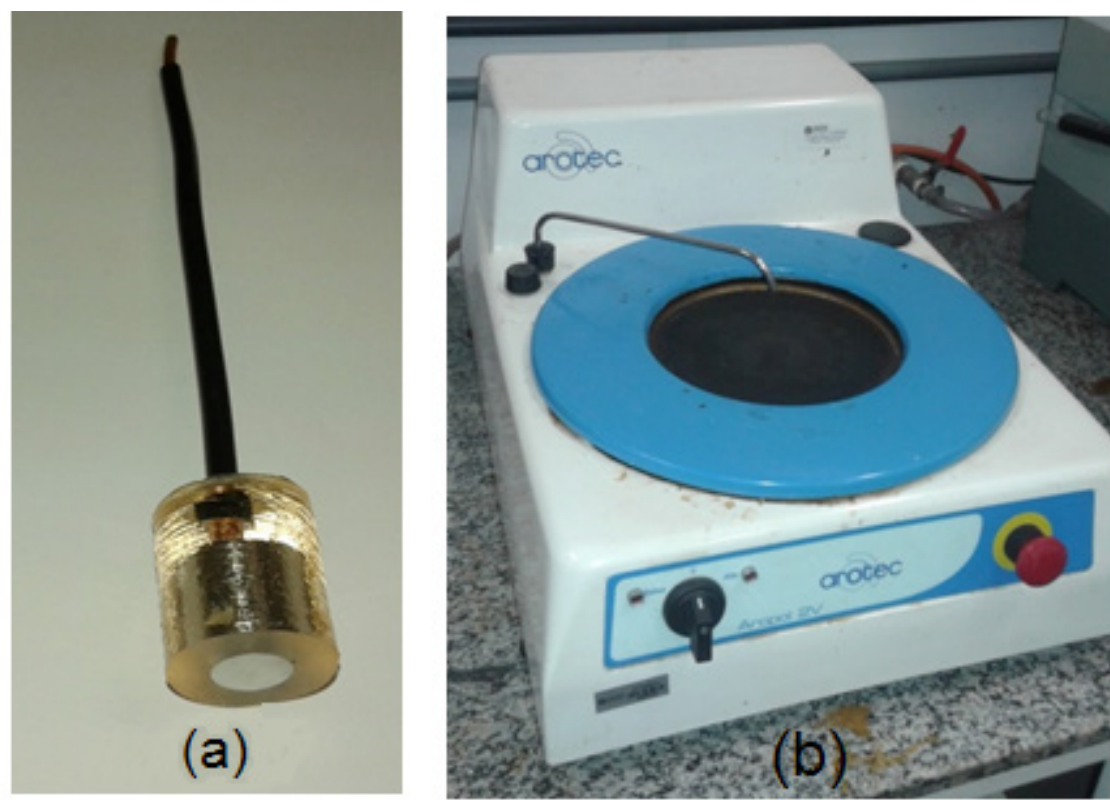

Fonte: Dos autores, 2018

\section{PREPARAÇÃO DA SOLUÇÃO DE CLORETO FÉRRICO.}

O cloreto férrico hexa-hidratado $\left(\mathrm{FeCl}_{3} \cdot 6 \mathrm{H}_{2} \mathrm{O}\right)$, concentração $40 \%$, usado nos ensaios de polarização anódica foi de fornecimento da empresa Nusi Indústria Química, situado na cidade de Timóteo, MG.

A preparação da solução de cloreto férrico foi realizada a partir de uma solução de cloreto férrico hexa-hidratado $\left(\mathrm{FeCl}_{3} \cdot 6 \mathrm{H}_{2} \mathrm{O}\right)$ concentração de $40 \%$ em massa. Para os ensaios deste trabalho, a solução de cloreto férrico a $40 \%$ foi diluída conforme Tabela 2, com o acréscimo de água destilada para compor as soluções necessárias aos ensaios a serem realizados.

Tabela 2 - Solução de cloreto férrico hexa-hidratado $\left(\mathrm{FeCl}_{3} \cdot 6 \mathrm{H}_{2} \mathrm{O}\right)$ usado nos ensaios.

\begin{tabular}{cccc}
\hline $\begin{array}{c}\text { Solução de cloreto férrico hexa- } \\
\text { hidratado }\left(\mathrm{FeCl}_{3} \cdot 6 \mathrm{H}_{2} \mathrm{O}\right) \text { concentração } \\
40 \% \text { em massa. }\end{array}$ & $\begin{array}{c}\text { Quantidade de água destilada } \\
\text { a acrescentar } \\
\text { (em massa) }\end{array}$ & $\begin{array}{c}\text { Volume final da } \\
\text { Solução diluída } \\
\text { (em massa) }\end{array}$ \\
\hline 100 & 0,00 & 100,00 & Concentração $40 \%$ \\
\hline 100 & 33,33 & 133,33 & Concentração $30 \%$ \\
\hline 100 & 100,00 & 200,00 & Concentração 20\% \\
\hline 100 & 207,69 & 307,69 & Concentração 13\% \\
\hline
\end{tabular}

Fonte: Dos autores, 2018.

Após o preparo das soluções em suas respectivas concentrações, foi realizada a medição do $\mathrm{pH}$, utilizando-se medidor de $\mathrm{pH}$, conforme mostrado na Figura 4. 
Figura 4 - Equipamento usado para medir o pH das soluções de cloreto férrico.

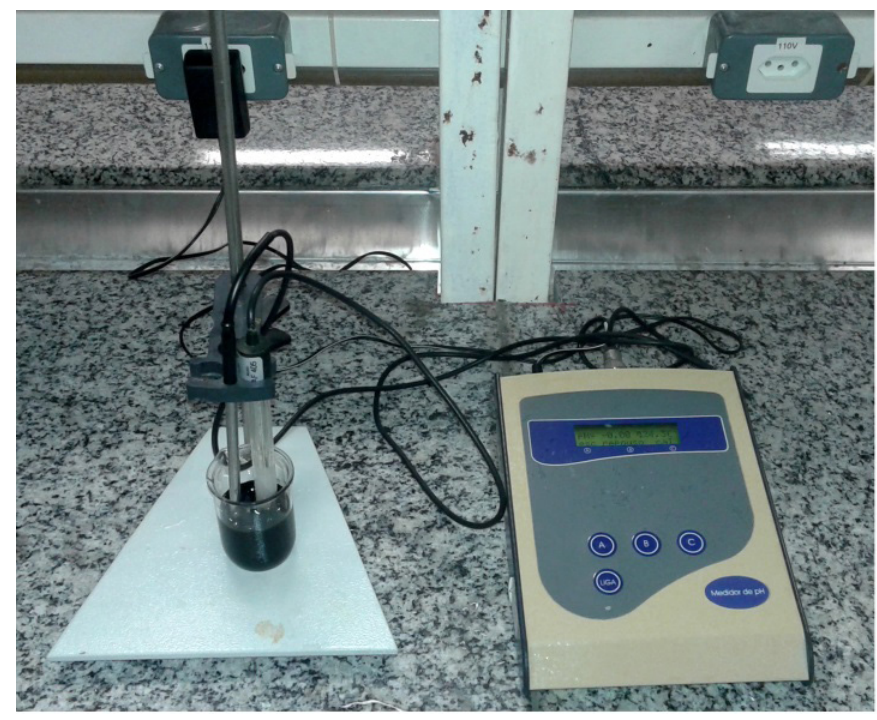

Fonte: Dos autores, 2018

A Tabela 3 apresenta os valores do pH para as soluções de cloreto férrico a serem usados nos ensaios de polarização anódica.

Tabela 3 - pH das soluções de cloreto férrico hexa-hidratado $\left(\mathrm{FeCl}_{3} \cdot 6 \mathrm{H}_{2} \mathrm{O}\right)$ a serem usados nos ensaios de polarização anódica.

\begin{tabular}{cc}
\hline $\begin{array}{c}\text { Concentração (em massa) solução de cloreto férrico } \\
\text { hexa-hidratado }\left(\mathrm{FeCl}_{3} \cdot 6 \mathrm{H}_{2} \mathrm{O}\right)\end{array}$ & $\mathrm{pH}$ \\
\hline $40 \%$ & $-0,58$ \\
$30 \%$ & $-0,15$ \\
$20 \%$ & 0,39 \\
$13 \%$ & 0,69 \\
\hline
\end{tabular}

Fonte: Dos autores, 2018.

Para cada ensaio, foi utilizado $75 \mathrm{ml}$ de solução de cloreto férrico hexa-hidratado $\left(\mathrm{FeCl}_{3} \cdot 6 \mathrm{H}_{2} \mathrm{O}\right)$, concentração conforme a Tabela 4 para o aço 304. 
Tabela 4 - Volume e concentração de cloreto férrico hexa-hidratado $\left(\mathrm{FeCl}_{3} \cdot 6 \mathrm{H}_{2} \mathrm{O}\right)$ usado nos ensaios com o aço 304.

\begin{tabular}{ccccc}
\hline Ensaio & Aço & $\begin{array}{c}\text { Concentração (em massa) Solução } \\
\text { de cloreto férico hexa-hidratado } \\
\left(\mathrm{FeCl}_{3} \cdot 6 \mathrm{H}_{2} \mathrm{O}\right)\end{array}$ & $\begin{array}{c}\text { Volume da solução usado } \\
\text { no ensaio }\end{array}$ & $\begin{array}{c}\text { Temperatura de } \\
\text { realização do ensaio }\end{array}$ \\
\hline 1 & & $40 \%$ & & \\
2 & $30 \%$ & $75 \mathrm{ml}$ & \\
3 & 304 & $20 \%$ & & \\
4 & & $13 \%$ & $75 \mathrm{ml}$ & \\
\hline 5 & & $40 \%$ & & $35^{\circ} \mathrm{C}$ \\
6 & 304 & $30 \%$ & & \\
7 & & $20 \%$ & & \\
8 & & $13 \%$ & & \\
\hline 9 & & $40 \%$ & & \\
10 & $30 \%$ & $20 \%$ & & \\
11 & & $13 \%$ & & \\
12 & & &
\end{tabular}

Fonte: Dos autores, 2018.

\section{ENSAIO DE POLARIZAÇÃO POTENCIODINÂMICA ANÓDICA}

Os ensaios de polarização potenciodinâmica anódica foram realizados no laboratório de metalurgia da UEZO. 0 estudo eletroquímico do aço 304 foi realizado a partir de medidas do potencial de circuito aberto e determinação das curvas de polarização potenciodinâmica anódica nas seguintes condições:

Para ambas as amostras do aço 304 , foi usado solução de cloreto férrico hexa-hidratado $\left(\mathrm{FeCl}_{3} \cdot 6 \mathrm{H}_{2} \mathrm{O}\right)$, concentração $40 \%, 30 \%, 20 \%$ e $13 \%$ em massa, varredura de potencial de $-0,8 \mathrm{~V}$ a $1 \mathrm{~V}$, taxa de $1 \mathrm{mV} / \mathrm{s}$ e temperatura de $25^{\circ} \mathrm{C}, 35^{\circ}$ e $50^{\circ} \mathrm{C}$.

Os ensaios foram conduzidos em um sistema potenciostato/galvanostato PGSTAT 20 da AUTOLAB com célula provida de três eletrodos, no qual se utilizou, como eletrodo de trabalho, os aços 304 , como contra eletrodo, utilizou-se um fio de platina enrolado na forma espiral com área superior a das amostras e, como eletrodo de referência, utilizou-se o eletrodo de prata cloreto de prato $(\mathrm{Ag} / \mathrm{AgCl})$. A Figura 5 mostra o desenho esquemático da célula eletroquímica e o esquema de ligação dos eletrodos no potenciostato. 
Figura 5 - (a) desenho esquemático da célula eletroquímica e (b) esquema de ligação dos eletrodos no potenciostato.

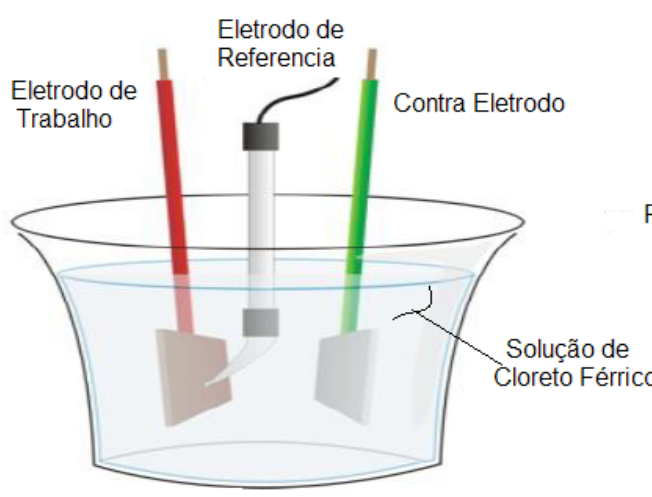

(a)

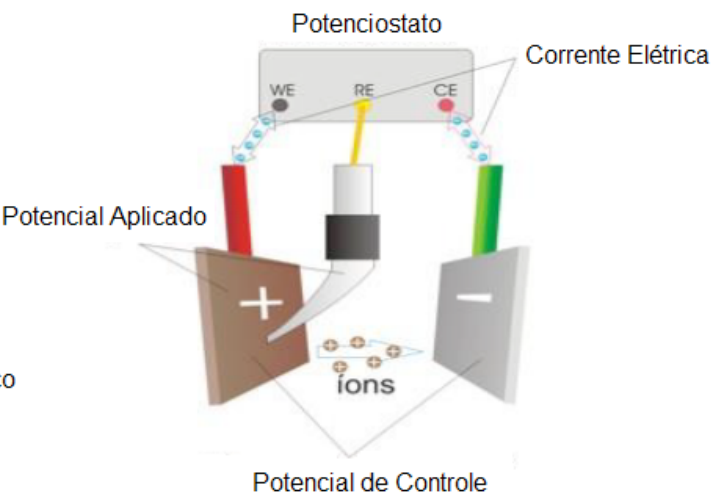

(b)

Fonte:Internet - https://pt.wikipedia.org/wiki/Potenciostato - Acesso em: 26 nov. 2018

Como eletrólito, foram utilizadas soluções de cloreto férrico nas concentrações de $40 \%, 30 \%$, $20 \%$ e $13 \%$. A amostra, os eletrodos e o contra eletrodo ficaram alinhados dentro do Becker para a realização dos ensaios. A varredura do potencial sempre se iniciou após 5 minutos de imersão. Os dados de potencial aplicado e a corrente medida foram exportados para o software Origin 8 para elaboração dos gráficos. A partir do gráfico de Potencial (em $\mathrm{mV}$ ) versus densidade de corrente $\left(\mathrm{mA} / \mathrm{cm}^{2}\right)$, foram determinados os parâmetros eletroquímicos $\mathrm{E}_{\text {pite }}$ e $\mathrm{I}_{\text {pite. }}$.

A Figura 6 mostra o potenciostato da marca Autolab e a ligação dos eletrodos no Autolab do laboratório de metalurgia da UEZO.

Figura 6 - (a) Autolab usado para a realização dos ensaios de polarização anódico, (b) ligação dos eletrodos no Autolab.
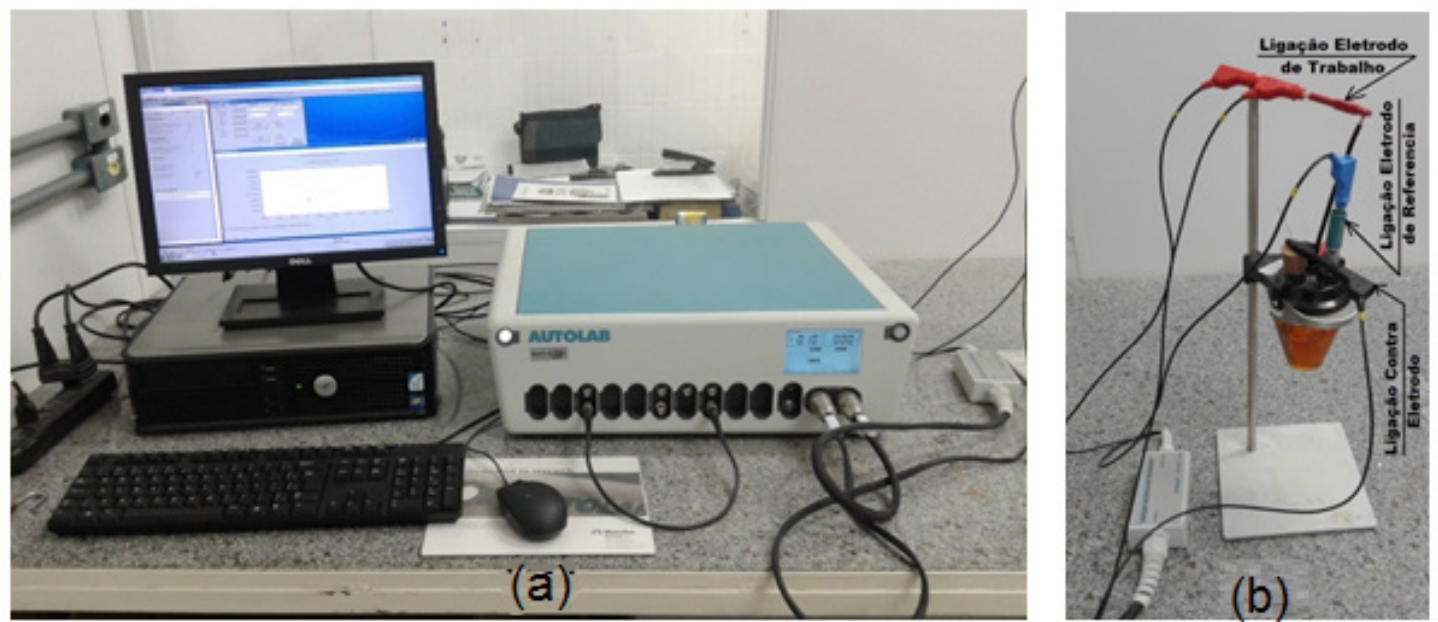

Fonte: Dos autores, 2018.

Os ensaios de polarização potenciodinâmica anódica foram realizados nas temperaturas de $25^{\circ} \mathrm{C}, 35^{\circ} \mathrm{C}$ e $50^{\circ} \mathrm{C}$. Para realização dos ensaios nas temperaturas de $35^{\circ} \mathrm{C}$ e $50^{\circ} \mathrm{C}$, foi usado fita de aquecimento ligado a um graduador de temperatura, conforme Figura 7. 
Figura 7 - Graduador de temperatura e fita de aquecimento usado para o aquecimento da solução de cloreto férrico nas temperaturas de $35^{\circ} \mathrm{C}$ e $50^{\circ} \mathrm{C}$.

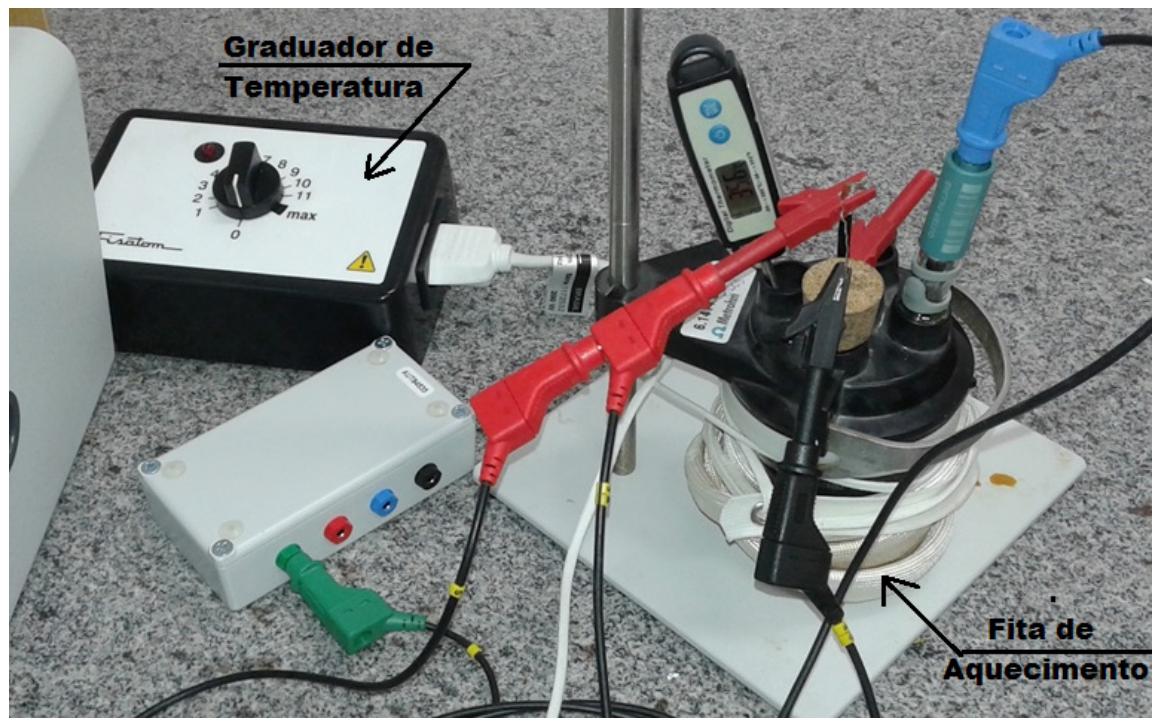

Fonte: Dos autores, 2018.

Foram determinados os potenciais de pite, obtendo-se as curvas de polarização das amostras imersas em soluções de cloreto férrico, com concentração variando de $13 \%, 20 \%, 30 \%$ e $40 \%$ em massa (\% de massa/massa) (CAKIR, 2006; BRUZZONE; REVERBERI, 2010). A varredura do potencial sempre se iniciou após 5 minutos de imersão. A partir do gráfico de Potencial (em $\mathrm{mV}$ ) versus densidade de corrente $\left(\mathrm{mA} / \mathrm{cm}^{2}\right)$, foram determinados os parâmetros eletroquímicos Potencial de Pite $\left(\mathrm{E}_{\text {pite }}\right)$ e Corrente de Pite $\left(I_{\text {pite }}\right)$. Nos testes, o potencial foi variado continuamente de $-0,8 \mathrm{~V}$ a $1,0 \mathrm{~V}$, com a taxa de $1,0 \mathrm{mV} / \mathrm{s}$ e nas temperaturas de $25^{\circ} \mathrm{C}, 35^{\circ} \mathrm{C}$, e $50^{\circ} \mathrm{C}$. As curvas de polarização foram obtidas a partir dos gráficos $\mathrm{E}$ x I em um equipamento potenciostato-galvanostato PGSTAT 20 da Autolab, conforme Figura 6a acoplado a um microcomputador para aquisição e tratamento dos dados (Princeton, Corr-4, 2018; Princeton, Corr-1, 2018). Os dados de potencial aplicado e a corrente medida foram exportados para elaboração dos gráficos.

\section{RESULTADOS}

As Figuras (8a), (8b), (8c) e (8d) apresentam as curvas características de polarização anódica linear do aço inoxidável 304 obtidas em solução de cloreto férrico nas concentrações de $13 \%, 20 \%, 30 \%$ e $40 \%$ em massa e nas temperaturas de $25^{\circ} \mathrm{C}, 35^{\circ} \mathrm{C}$ e $50^{\circ} \mathrm{C}$.

A Tabela 5 apresenta os valores de $\mathrm{E}_{\text {pite }}$ e $\mathrm{i}_{\text {pite }}$ extraídos das curvas de polarização anódica da Figura 8 para o aço inoxidável 304. 
Figura 8 - Curvas de polarização anódica linear para o aço 304 em solução de cloreto férrico.

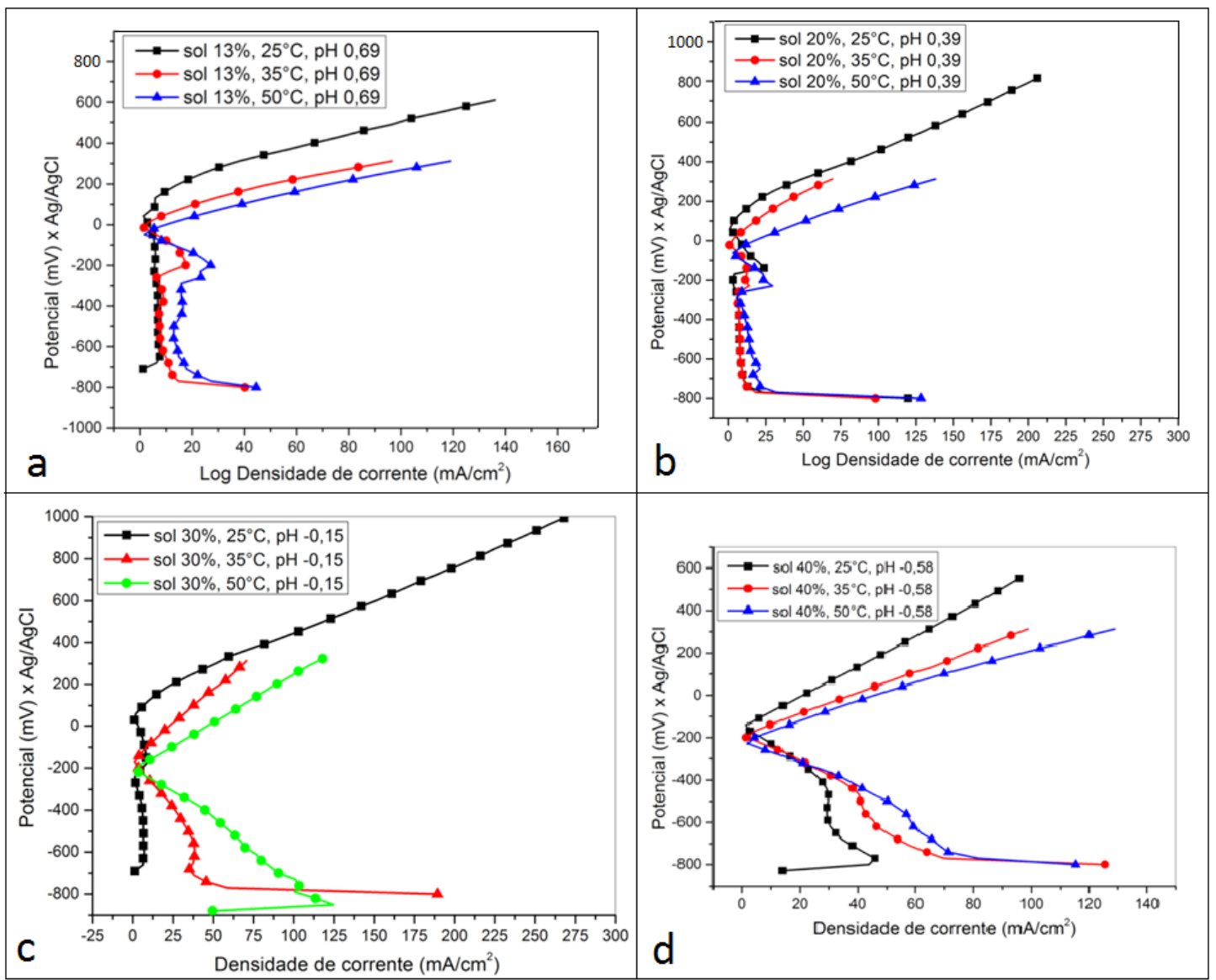

Fonte: Dos autores, 2018

Tabela 5 - Valores de $\mathrm{E}_{\text {pite }}$ e $\mathrm{i}_{\text {pite }}$ para o aço 304 em solução de cloreto férrico, extraídos das curvas de polarização anódica.

\begin{tabular}{ccccc}
\hline $\begin{array}{c}\text { Solução de } \mathrm{FeCl} 3 \\
\text { (em massa) }\end{array}$ & $\mathrm{pH}$ & Temperatura & $\begin{array}{c}\text { Epite } \\
(\mathrm{mV})\end{array}$ & $\begin{array}{c}\text { Ipite } \\
(\mathrm{mA} / \mathrm{cm} 2)\end{array}$ \\
\hline \multirow{2}{*}{$13 \%$} & $25^{\circ} \mathrm{C}$ & 86,85 & 0,561 \\
& 0,69 & $35^{\circ} \mathrm{C}$ & $-14,6$ & 1,57 \\
& $50^{\circ} \mathrm{C}$ & $-48,5$ & 1,63 \\
\hline \multirow{2}{*}{$0 \%$} & $25^{\circ} \mathrm{C}$ & 56,72 & 0,76 \\
& 0,39 & $35^{\circ} \mathrm{C}$ & $-22,5$ & 0,835 \\
& & $50^{\circ} \mathrm{C}$ & $-60,52$ & 3,16 \\
\hline $30 \%$ & $25^{\circ} \mathrm{C}$ & 31,59 & 0,936 \\
& & $35^{\circ} \mathrm{C}$ & $-168,8$ & 1,09 \\
& $-0,15$ & $50^{\circ} \mathrm{C}$ & $-188,4$ & 3,57 \\
\hline & & $25^{\circ} \mathrm{C}$ & $-138,7$ & 1,47 \\
& & $35^{\circ} \mathrm{C}$ & $-198,8$ & 1,5 \\
& & $50^{\circ} \mathrm{C}$ & $-228,9$ & 1,85 \\
\hline
\end{tabular}

Fonte: Dos autores, 2018. 
A Figura 9 mostra as imagens dos pites que foram formados nas amostras do aço 304 durante os ensaios de polarização anódica.

Figura 9 - Pites formado no aço 304 em ensaio de polarização anódica em solução de cloreto férrico (\% em massa). (A) $\mathrm{T}=25^{\circ} \mathrm{C}$, solução $13 \%$ e pH 0,69 . (B) $\mathrm{T}=25^{\circ} \mathrm{C}$, solução $20 \%$ e pH 0,39 (C) $\mathrm{T}=25^{\circ} \mathrm{C}$, solução $30 \%$ e pH $-0,15$. (D) $\mathrm{T}=25^{\circ} \mathrm{C}$, solução $40 \%$ e pH $-0,58$. (E) $\mathrm{T}=35^{\circ} \mathrm{C}$, solução $13 \%$ e pH 0,69 . (F) $\mathrm{T}=35^{\circ} \mathrm{C}$, solução $20 \%$ e pH $0,39(\mathrm{G}) \mathrm{T}=35^{\circ} \mathrm{C}$, solução $30 \%$ e pH $-0,15$. (H) $\mathrm{T}=35^{\circ} \mathrm{C}$, solução $40 \%$ e pH $-0,58$. (J) $\mathrm{T}=50^{\circ} \mathrm{C}$, solução $13 \%$ e pH 0,69 . (B) $\mathrm{T}=50^{\circ} \mathrm{C}$, solução $20 \%$ e pH 0,39 (C) $\mathrm{T}=50^{\circ} \mathrm{C}$, solução $30 \%$ e pH -0,15. (D) $\mathrm{T}=50^{\circ} \mathrm{C}$, solução $40 \%$ e pH $-0,58$.

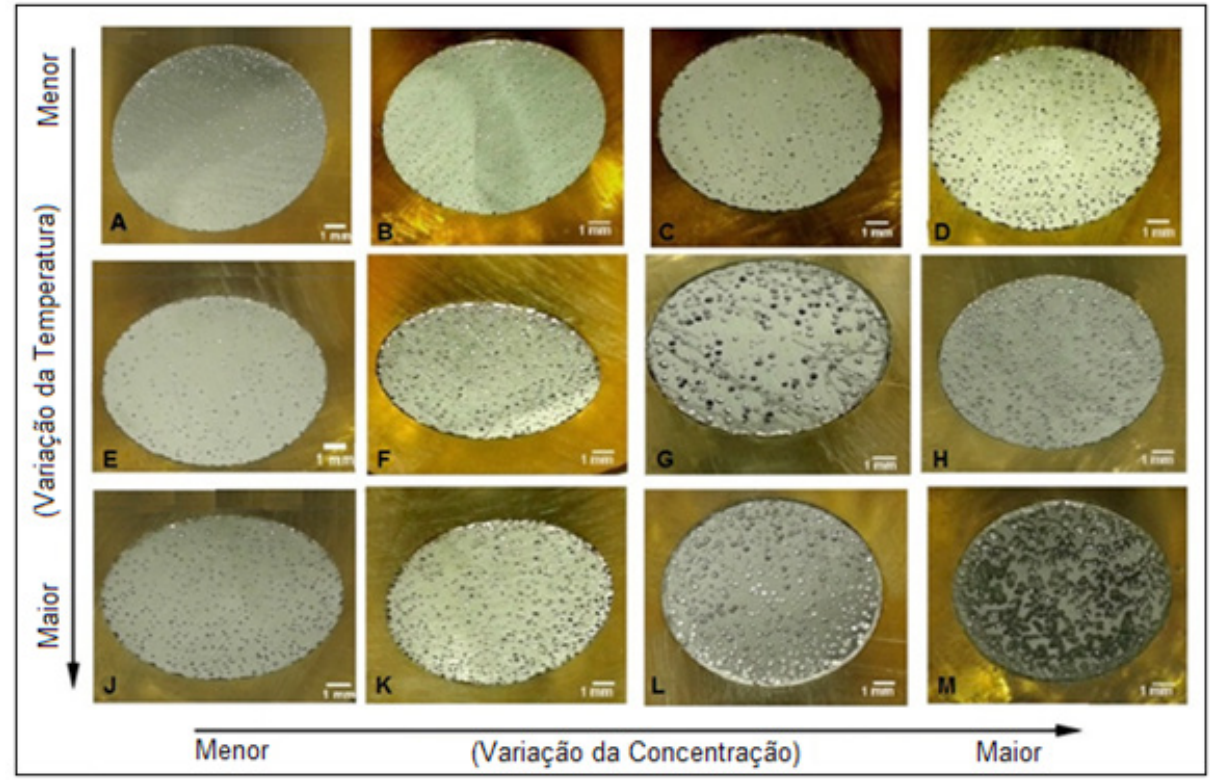

Fonte: Dos autores, 2018

A Figura 10 apresenta a variação do valor de $\mathrm{E}_{\text {pite }}$ em relação à variação da concentração da solução de cloreto férrico de $13,20,30$ e $40 \%$ para o aço 304 , nas temperaturas de $25^{\circ} \mathrm{C}, 35^{\circ} \mathrm{C}$ e $50^{\circ} \mathrm{C}$.

Figura 10 - Variação do valor de $\mathrm{E}_{\text {pite }}$ em solução de cloreto férrico, nas temperaturas de $25^{\circ} \mathrm{C}, 35^{\circ} \mathrm{C} \mathrm{e}$ $50^{\circ} \mathrm{C}$ para o aço 304 .

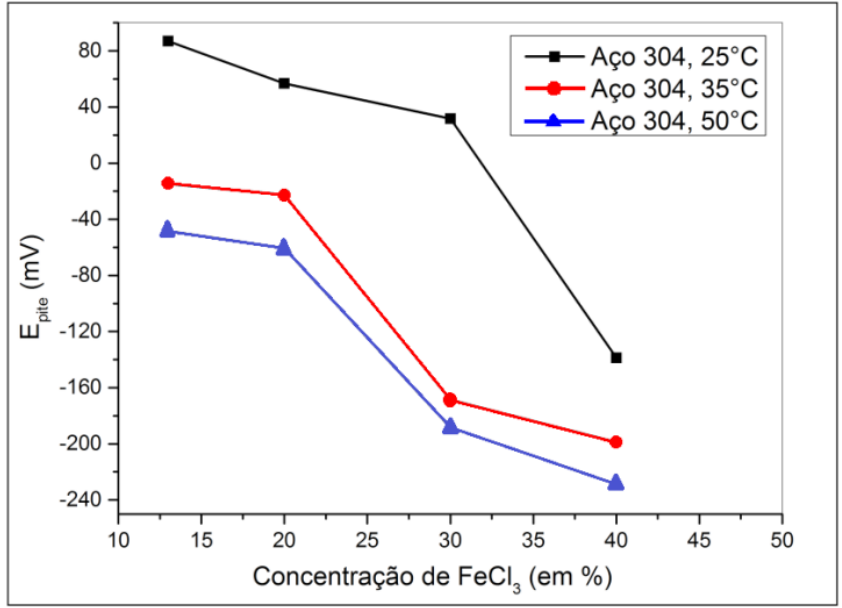

Fonte: Dos autores, 2018 


\section{DISCUSSÃO}

Conforme os dados apresentados na Tabela 5, quanto maior a concentração do produto corrosivo e as temperaturas, menores serão os valores de $\mathrm{E}_{\text {pite }}$. Quando ocorre a formação dos pites, implica que o produto corrosivo destruiu a camada passiva responsável pela proteção do aço contra a corrosão, onde o material ensaiado passa do regime passivo para o regime tranpassivo (CROOKES, 2007; RIVIE, 2011). Em ambas as curvas da Figuras 8, observa-se a mudança da região passiva para a região tranpassiva, com o disparo da corrente de polarização que se mantém linear.

Observa-se, para o aço 304, que, após a quebra da camada passiva, ocorreu a formação de pite, conforme as Figuras (9A), (9B), (9C), (9D), (9E), (9F), (9G), (9H), (9J), (9K), (9L) e (9M), (FONG-YUAN, 2012; KHATAK; RAJ, 2002). As análises das imagens da Figura 9 mostram um aumento contínuo da densidade de pites, conforme ocorre o aumento da concentração da solução de cloreto férrico (indicado pela seta da esquerda para a direita na Figura 9) e o aumento da temperatura (indicado pela seta de cima para baixo na Figura 9). 0 aumento contínuo da densidade de pites, conforme observado na Figura 9, indica que a integridade do filme é fortemente afetada pelo alto teor de cloreto, isto é, a resistência da camada passiva diminui, quando o teor de cloreto aumenta (PATIL et al, 2018;). A quebra da camada passiva do aço 304 estudado é mais favorável para as maiores concentrações do teor de cloreto presente na solução de cloreto férrico, devido à mais alta pressão e densidade de íons de cloretos sobre a superfície da liga (XIN; MA; WANG, 2017; RATHOD; SAPKAL; CHANMANWAR, 2017; SZKLARSKA- SMIALOWSKA, 1986).

Observa-se, nas curvas da Figura 10, que ocorre uma grande variação do valor do $\mathrm{E}_{\text {pite }}$ apresentado na curva do $A$ ço $304,25^{\circ} \mathrm{C}$ para a curva do $A c ̧ o ~ 304,35^{\circ} \mathrm{C}$, enquanto que a variação do $\mathrm{E}_{\text {pite' }}$ apresentado na curva do Aço $304,35^{\circ} \mathrm{C}$ para a curva do $A$ ço $304,50^{\circ} \mathrm{C}$ a variação do $\mathrm{E}_{\text {pite }}$ é menor. Para a temperatura acima de $35^{\circ} \mathrm{C}$, o tempo para iniciar o processo de dissolução do aço 304 é menor, quando comparado com a temperatura de $25^{\circ} \mathrm{C}$, onde o processo de dissolução do aço 304 será mais lento. No processo de usinagem fotoquímica, as peças ganham forma, devido à dissolução do metal em áreas pré-selecionadas. Isso demonstra que, para o processo de usinagem fotoquímica, é mais viável (recomendável) que o processo de ataque químico, com o uso de solução de cloreto férrico, seja realizado em temperaturas acima de $35^{\circ} \mathrm{C}$ (acima de $35^{\circ} \mathrm{C}$ a continuidade da queda do $\mathrm{E}_{\text {pite }}$ é baixa) (PATIL; CHANMANWAR, 2018; MISAL; SADAIAH, 2018)

\section{CONCLUSÃO}

Conforme as análises das curvas de polarização anódica apresentada na Figura 8, e resumido na Tabela 5, para o aço 304, verificou-se que quanto maior a temperatura e a concentração da solução de cloreto férrico, menores serão os valores dos $\mathrm{E}_{\text {pite }}$. A densidade e o tamanho dos pites no aço inoxidável 304 apresentados na Figura 9 aumentaram, conforme ocorreu o aumento da concentração da solução de cloreto férrico e da temperatura.

Os valores baixos do $\mathrm{E}_{\text {pite }}$ na Tabela 5 indicam que a corrosão da superfície exposta do aço inoxidável 304 atacada com solução de cloreto férrico ocorrerá rápido, havendo uma grande perda de massa em um curto espaço de tempo.

Essa característica do material em contato com a solução de cloreto férrico com alto teor de cloreto e com temperatura acima de $35^{\circ} \mathrm{C}$ contribui para uma grande perda de massa em um curto espaço de tempo, sendo favorável para o processo de usinagem fotoquímica, onde a superfície atacada perde massa, alterando a superfícies do aço, dando forma a peça desejada. Quanto mais rápido ocorrer o ataque da superfície pela ação da solução de cloreto férrico, mais eficiente será o processo de usinagem fotoquímica para aço inoxidável 304. 
Pela Figura 10, conclui-se que o processo de usinagem fotoquímica do aço inoxidável 304 terá uma melhor eficiência a partir da temperatura de $35^{\circ} \mathrm{C}$, onde verifica-se que, a partir dessa temperatura, a queda do $\mathrm{E}_{\text {pite }}$ é menor, quando se compara à queda no $\mathrm{E}_{\text {pite }}$ da temperatura de $25^{\circ} \mathrm{C}$ até a temperatura de $35^{\circ} \mathrm{C}$.

\section{REFERÊNCIAS}

ABATE, Kenneth. Photochemical Etching of Metals. BMC Industries - Metal Finishing, Cortland, N.Y, 1997. AL-ETHARI, Haydar A. H; ALSULTANI, Kadhim Finteel; DAKHIL, Nasreen F. Variables Affecting the Chemical Machining of Stainless Steel 420. International Journal of Engineering and Innovative Technology, v. 3, p.210-216, 2013.

ALLEN, David M. Photochemical Machining: From Manufacturing's Best Kept Secret to a \$6 Billion per annum, Rapid Manufacturing Process. CIRP Journal of Manufacturing Systems, UK. 2005.

ALLEN, David M; ALMOND, H. J. A. Characterization of aqueous ferric chloride etchants used in industrial photochemical machining. Journal of Materials Processing Technology, UK, v.149, p. 238-245, 2004.

BRUZZONE, A. A. G; REVERBERI, A.P. An Experimental Evaluation of an Etching Simulation Model for Photochemical Machining. CIRP Annals - Manufacturing Technology, v. 59, p. 255-258, 2010.

CAKIR, O. Copper etching with cupric chloride and regeneration of waste etchant. Journal of Materials Processing Technology, Turkey. v. 175, p. 63-68, 2006.

CARBÓ, H. M. Aço Inoxidável: aplicações e especificação. São Paulo: Acelor Mital Inox Brasil, 2008. CROOKES, Roger. Pickling and Passivating Steel. Materials and Applications Series, V 4, 2. ed. Euro Inox, 2007.

DAVIS, P. J.; OVERTURF G. E. Chemical machining as a precision material process: Work performed under the auspices of the US Department of Energy by the Lawrence Livermore National Laboratory under. US, v. 8, p. 67-71, 1986.

EL-HOFY, Hassan. Advanced Machining Processes. Nontraditional and Hybrid Machining Processes. Egypt: McGraw-Hill, 2005. 253p.

FONG-YUAN Ma. Corrosive Effects of Chlorides on Metals, Pitting Corrosion, Prof. Nasr Bensalah (Ed.), InTech, 2012. Disponível em:<http://www.intechopen.com/books/pitting corrosion/corrosive-effectsof-chlorides-on-metals>. Acesso em: 15 dez. 2018.

GEMELLI, Enori. Corrosão de materiais metálicos e sua caracterização. 3. ed. Rio de Janeiro: LTC, 2001.183p.

GENTIL, V. Corrosão. 6. ed. Rio de Janeiro. LTC, 2011. 373p.

KARJALAINEN, Pentti; HERTZMAN, Staffan. European Stainless Steel. $6^{\circ}$ European Stainless Steel Conference, Science and Market; Helsinki, Finland; Jernkontoret, 2008. 842p.

KIM, J-H.; MIRZAEI, A, H.; KIM, Woo; KIM, S. Sub. Facile fabrication of superhydrophobic surfaces from austenitic stainless steel (AISI 304) by chemical etching. Applied Surface Science p. 1-29, 2017. 
KHATAK, H. S.; RAJ, Baldev. Corrosion of austenitic stainless steels: Mechanism, Mitigation and Monitoring. 1. ed. India: Alpha Science, 2002. 388p.

MISAL, N.D.; SADAIAH, M. Multi-Objective Optimization of Photochemical machining of Inconel 601 using Grey Relational Analysis. Materials Today: Proceedings, V.5, p.5591-5600, 2018.

PATIL, Deepakkumar H; THORAT, Shrikant B, KHAKE, Rohit A; and MUDIGONDA, Sadaiah. Comparative study of $\mathrm{FeCl} 3$ and $\mathrm{CuCl} 2$ on geometrical features using Photochemical Machining of Monel 400. Procedia CIRP, V.68, p.144 - 149, 2018.

PATIL, Omkar; CHANMANWAR, Rahul. Multi-Objective Optimization of Photochemical Machining by Using GRA. Analysis and Optimization of Photochemical Machining on Copper. Procedia Computer Science, v.133 p.464-470, 2018.

PRINCETON APPLIED RESEARCH. Electrochemical Instruments Division: Electrochemistry and Corrosion Overview and techniques. Application Note CORR-4. Disponível em: <http://www.princetonappliedresearch. com/Literature/index.aspx>, Acesso em : 07 dez. 2018.

Princeton Applied Research. Electrochemical Instruments Division: Electrochemistry and Corrosion Overview and techniques. Application Note CORR-1. Disponível em: <http://www.princetonappliedresearch. com/Literature/index.aspx>, Acesso em : 07 dez. 2018.

RATHOD, G. R; SAPKAL, S. U.; CHANMANWAR, R. M. Multi-Objective Optimization of Photochemical Machining by Using GRA. Materials Today. Proceedings v.4, p.10830-10835, 2017.

RIVIE, R. Winston. Uhlig's Corrosion Handbook. 3. ed. USA: Wiley, 2011. 1296p.

SZKLARSKA-SMIALOWSKA, Z. Pitting Corrosion of Metals, National Association of Corrosion Engineers. Houston: Texas, 1986.

TEHRANI, A. Fadaei; IMANIAN, E. A new etchant for the chemical machining of St304. Journal of Materials Processing Technology, USA, v. 149, p. 404-408, 2004.

WEl, Wang; DI, Zhu; ALLEN, David M.; ALMOND, Heather J. A. Non-traditional Machining Techniques for Fabricating Metal Aerospace Filters. Chinese Journal of Aeronautics v.21, p.441-447, 2008.

WANGIKAR, Sandeep Sitaram; PATOWARI, Promod Kumar, MISRA, Rahul Dev. Parametric Optimization for Photochemical Machining of Copper using Overall Evaluation Criteria. Materials Today: Proceedings v.5, p. $4736-4742,2018$.

XIN, Fei; MA, Ting; WANG Qiuwang. Spray etching rate development of stainless steel in the etchant for printed circuit heat exchanger channels. Energy Procedia, V.105, p.4828 - 4835, 2017.

ZHANG, Jinyu; MENG, Yonggang. A study of surface texturing of carbon steel by photochemical machining. Journal of Materials Processing Technology, v.212, p.2133-2140, 2012. 